\title{
Reencontrando identidad. Apuntes metodológicos para el estudio de los judíos en América Latina
}

Judit Bokser-Liwerant

En la seria revisión analítica y crítica que Luisa Passerini lleva a cabo en torno a las relaciones entre conocimiento histórico e historia oral, y sobre los alcances y limitaciones que esta última ha tenido en su desarrollo, ubica un momento en que la historia oral se reconoce a sí misma como "manifestación de la necesidad de reencontrar una identidad". 'Inicialmente contextualizado en la década de los sesenta, tal como se da en los Estados Unidos, aparece como resultado de procesos sociales así como de desarrollos disciplinarios, entre los que destaca la autonomia que asume el estudio del folclor y su deslinde de la antropología en su acercamiento a la historia. A su vez, incide sobre la configuración de ese momento de su desarrollo, la elaboración de la propuesta de una history of the people en el seno de la propia disciplina histórica. En este clima, nos recuerda Passerini, la historia oral en función del reencuentro de una identidad no será privativa de algunos grupos sociales, sino que se extenderá a todos. "La experiencia del inmigrado miserable que vaga en un mundo extraño del que no conoce ni a los habitantes ni la lengua", 2 parece entonces convertirse en una experiencia generalizada y esencial a las ciudades del capitalismo desarrollado, y representa el deterioro de las relaciones humanas. Así, y desde una perspectiva sociocultural, la ruptura de marcos referenciales y la debilidad e inseguridad que resultarian de este estado anómalo, habrian conducido al individuo a explorar y buscar un pasado, un lugar de origen, que pueda proporcionar un anclaje compensatorio a la "sospecha", temor tal vez, de no existir plenamente en el presente. "Historia-memoriacontinuidad e identidad del yo se unen como una sola pérdida frente al cambio intemporal que impera".

De este modo, la historia oral "como producto y espejo de la decadencia de la conciencia contemporánea y de la aspiración a una identidad" habria tendido a sacralizar el pasado todo, a magnificar y fundirse en un revival y a generar, entre otros múltiples efectos, una complacencia pasiva con el presente como resultado del refugio en ese pasado.

Entre estos efectos sociales, todos ellos significativos, nos interesa enfatizar aquel peligro que, lúcidamente nos advierte Passerini, acecha a la historia oral, el de la obsesión por la escasez del tiempo antes de la destrucción final de los testimonios vivientes. La pérdida de distancia del historiador, expresada en la magnifica-

' Luisa Passerini, Storia Orale. Vita Quotidiana e Cultura Materiale delle Clasi Subalterne, Torino, Rosenberg \& Sellier, 1987, p. 9.

- Ibid.

${ }^{3}$ Ibid. 
ción del fin del pasado, habría conducido así a una carrera angustiosa contra el tiempo, sacrificando rigor y método, en una palabra: oficio -el del historiador-, por poder realizar la máxima proustiana -en busca del tiempo perdido- encarnada en un instrumento de la modernidad: la grabación.

La falta de tiempo, dirá Passerini, "reduce la conciencia histórica a una grabación y hace del historiador un archivista." 4 En efecto esta amenaza, que se ha manifestado en el reduccionismo del oficio y en su consecuente pérdida de potencial explicativo, debe aparecer como una preocupación de primer orden en toda reflexión metodológica. Si bien este problema no ha sido privativo de la historia oral de grupos étnicos, o de inmigrantes, pues más que derivarse del objeto de estudio parece estar implicado en el ámbito metodológico -cuando el método se ha visto, a su vez, reducido a técnica-, en nuestro caso aparece como particularmente relevante. En todo caso, la incorporación de la expresión "reencontrando identidad", a estos apuntes metodológicos se desprende de la certidumbre de que la dimensión de identidad del grupo estudiado o del estudioso no es necesariamente, y sin más, la causa de este reduccionismo.

En una aproximación inicial orientada a destacar la potencialidad de la historia oral, para el estudio sociopolitico y cultural de los judios en América Latina, quisiéramos apuntar su funcionalidad multidisciplinaria. Ella puede permitirnos tender aquellos puentes necesarios y significativos para la construcción de nuestro campo de estudio superando asi las fragmentaciones asociadas a toda especialización disciplinaria. No vemos en la historia un campo pasivo y receptivo de confluencia conceptual de las ciencias sociales sino, por el contrario, un actor fundamental a partir de cuya perspectiva disciplinaria podemos acceder a una delimitación y comprensión integral de nuestro objeto de estudio.

La historia oral como método -en el entendido de que éste, antes que una cuestión técnica es una cuestión teórica-, parece ser un campo propicio para esta reflexión, dificil, por cuanto su propia identidad teórica y metodológica ha sido diversa y continúa siendo objeto de controversia.

En todo caso, avancemos señalando que conceptualizamos a la historia oral como construcción de las fuentes para la construcción de la historia; ' historia oral para la investigación histórica y social y no como sustituto de ella, historia oral que permita al historiador ser historiador y no portavoz de la evidencia, ${ }^{6}$ cientifico y no relator, siendo que el testimonio, el relato del actor, su información y percepción tienen toda la fuerza y validez de la fuente. Como "reencuentro de identidad", debe por tanto deslindarse entre la memoria como recurso de conciencia y la identidad del actor histórico de la memoria como recurso del historiador.

Ciertamente, en el estudio de los judios de América Latina se ha dado determinada tendencia a recuperar el pasado como identi-

Op. cit., p. 11.

Op. cit. p. 18.

'Philippe Joutard, Esas voces que nos llegan del pasado, México, F. C. E., 1986, p. 297.

Paul Thompson, "Problems of method in Oral History", en Oral History, 1972, vol. 1 , núm. 4 , p. 1-7. 
dad originaria. En la medida en que el dato primigenio de la presencia judía en América Latina es precisamente el de la migración, el mundo del inmigrante -modelo por excelencia de identidad en crisis- pareció permitir el encuentro del pasado, el reencuentro del origen. Desde la optica del estudioso, del historiador oral, resultaria determinante el hecho de que en el proceso contemporáneo de búsqueda de opciones para articular la identidad judía, los origenes y la pertenencia histórica juegan un papel determinante. Tanto mayor en las generaciones posteriores al Holocausto, que no necesariamente encuentran en la tradición o en la religión el foco de articulación de su identidad. Precisamente, de estas generaciones han surgido los nuevos estudiosos de la realidad latinoamericana y entre los cuales, como en todos los movimientos de estudios étnicos, la investigación representa en gran medida un medio para autoconocerse, para "reencontrar identidad". De alli que una gran proporción de los académicos que gravitan en la construcción de este nuevo campo de estudios, sean ellos mismos de origen judíolatinoamericano.

Ahora bien, la funcionalidad de éste, como de todo quehacer histórico estará validada por las exigencias del conocimiento consigo mismo, en términos de verdad, y con su entorno en términos de compromiso. El énfasis deberá estar siempre presente en sus contenidos cognoscitivos al margen de su instrumentalidad. Sin embargo, ciertos riesgos han estado y están presentes: la fascinación por un pasado romantizado o la obsesión por el tiempo han conducido en muchas ocasiones a que el testimonio sustituya la investigación, a que el historiador devenga entrevistador y a que el actor "explique" su propia realidad. En otros términos, se ha confundido la construcción de las fuentes con la construcción del conocimiento. $O$ lo que es igualmente grave, se ha pensado que la construcción de la fuente -historia oral para la generación de archivos orales- puede llevarse a cabo sin estar mediada por el conocimiento de la materia. Historiadores y archivistas han advertido sobre los riesgos de esta inmediatez y enfatizado la conexión esencial entre ambos momentos.?

Ciertamente, los riesgos y las limitaciones pasadas y presentes no cancelan las potencialidades metodológicas de la historia oral. Regresemos al inicio: la inmigración, uno de los primeros temas con el que se inician sistemáticamente los estudios de los judíos en América Latina y en el que han procurado confluir las diferentes disciplinas. El campo es amplio: causas y razones de la inmigración; tipología: inmigración individual o colectiva, forzosa o voluntaria; politicas migratorias de los paises receptores, tiempos y ritmos, modalidades de incorporación, etc. ${ }^{10}$ Una multiplicidad de aspectos y perspectivas analíticas que se desprenden del hecho mismo que la inmigración estableció las bases de los modelos or-

${ }^{8}$ Gilbert Merkx y Judith Laikin Elkin (eds.), The Jewish Presence in Latin America, Boston, Allen \& Unwin, 1987, p. 4.

'Geoffrey Wigoder, Catalogue no. 3, Oral History Division, The Institute of Contemporary Jewry, The Hebrew University of Jerusalem, 1970, p. IX-XV.

${ }^{10}$ Cf. Haim Avni, Argentina y la historia de la inmigración judia, 1810-1950, Buenos Aires, Ed. AMIA \& Magnes Press, 1983; y, del mismo autor, "The Role of Latin America in Inmigration and Rescue During the Nazi Era", Colloquium Paper, Washington, Woodrow Wilson Center, 1986. 
ganizativos y culturales y determinó los papeles que los judíos jugaron en diversas esferas de la vida de los países latinoamericanos. " Sociología y demografia, economia, política e historia han acudido a atender este campo alternativa o simultáneamente.

Pero veamos nuevas ópticas. En uno de los actores de este fenómeno, el inmigrante, se conjugan las dimensiones psicosocial y psicohistórica de modo tal que su historia personal y de grupo se encuentra inextricablemente entretejida con el proceso histórico. ${ }^{12}$ En él confluyen las coordenadas necesarias para el estudio del hombre: biografía, historia y marcos sociales. ${ }^{13} \mathrm{~A}$ la vez, su pasado está marcado por la intersección de dos mundos -el viejo, el expulsor, y el nuevo, el receptor, mismos que en su figura se entrecruzan paradigmáticamente. Su incorporación a la historia como producto histórico y a su vez, como productor de historia puede permitirnos contextualizarlo y transformar su "historia" en documento para la historia. ${ }^{14} \mathrm{La}$ potencialidad metodológica de la historia oral nos proporciona asi un amplio espectro. En un extremo, historia oral como testimonio de la historia de los acontecimientos, ${ }^{15}$ que complementa, enriquece, y descubre nuevos datos de tipo múltiple: canales institucionales que facilitaron la inmigración, organismos asistenciales, subterfugios individuales y organizativos que permitieron superar "las puertas cerradas" a la inmigración, entre otros. De este modo los archivos orales pueden "ilustrar, enriquecer, matizar, completar y hacer viviente la reconstrucción de tendencia racionalizante que hacen los historiadores". ${ }^{16}$ Pero hacer viviente significa también la posibilidad de incorporar otra dimensión metodológica al estudio, aquella de las percepciones, de lo imaginario, de la subjetividad humana expresada en los discursos del hombre ${ }^{17}$ La historia oral nos permite entonces enriquecer y trascender el plano de la información sobre los hechos para acceder al de las representaciones mentales. ${ }^{18}$ Incorporar de este modo el hombre a la historia es introducir aquella vasta y rica dimensión que, por no ser material, no es menos real: valores, cosmovisiones, ideologías, imaginación colectiva; todo reduccionismo materialista o positivista se ve así cuestionado. A través de este recurso podemos recuperar otras formas de ser de las migraciones, las migraciones interiores, esto es, culturales. ${ }^{19}$

Asi planteado el potencial de la historia oral, dos consideraciones resultan pertinentes. En primer lugar, la subjetividad no es un impedimento para el estudioso ni debilita la relevancia de la

$" C f$. U. O. Schmeltz y Sergio Della Pergola, "La demografia de los judios de America Latina", Jerusalén, Rumbos, núms. 15 y 16, marzo y junio de 1986.

${ }^{12}$ Erik, Erikson, Historia personal y circunstancia histórica, Madrid, Alianza Editorial, 1979.

${ }_{13}^{13}$ Wright Mills, La imaginación sociologica, México, F.C.E., 1958.

14 Sara Itzigshon et al., Integración y marginalidad, Historias de vidas de inmigrantes judios en la Argentina, Buenos Aires, Ed. Pardes, 1985.

is Cf. Joutard, op. cit.

${ }^{16}$ D. A. Schnapper, en Joutard, op. cit., p. 255.

17 Luisa Passerini, "Work Ideology and Working Class Attitudes to Fascism", en Paul Thompson (ed.), Our Common History, Great Britain, Pluto Press, 1982, p. $54-78$.

${ }^{18}$ Cf. Joutard, op, cil.

${ }^{19}$ Lucette Valensi y Nathan Wachtel, Memoires Juives, París, Gallimard Julliard, 1986, p. 121 y ss. 
fuente, toda vez que tengamos claro que estamos accediendo al pasado desde la óptica del presente y por tanto, memoria no es sólo reconstrucción sino también significación actual. Y ésta debe ser descifrada, exige interpretación.

Por ello, y en segundo lugar, de no ser éste el caso, de renunciar a la construcción científica, está presente el riesgo de reintroducir nuevas formas de reduccionismo. Esta vez no serian "los hechos los que hablan" sino los testimonios. Sobre este riesgo ya se ha advertido. ya sea en términos de los defectos de sus cualidades, ${ }^{20}$ del rechazo a la teoría o de ausencia de distancia. ${ }^{21}$ La falta de mediación teórica afecta directamente la potencialidad cognoscitıva y metodológica, aunque esté acompañada de una progresiva sofisticación técnica.

De ahi que, y en relación a nuestra temática especifica, el método deba estar acompañado por aquellos cuestionamientos significativos que configuran y construyen el campo de estudio. Estos pueden ser diversos, responder a diferentes perspectivas disciplinarias $o$ analíticas y privilegiar alternativamente las múltiples dimensiones de la realidad. Así, si con la historia oral se busca acceder, a través del inmigrante, al complejo mundo de lo cultural, ello exigirá del estudioso un conocimiento serio y profundo de ese mundo que se gestó en ultramar. Dicho sintéticamente, el estudio de los judíos exige el conocimiento del judaísmo en su diversidad de experiencias, corrientes culturales, movimientos sociales e ideologias. El encuentro entre este bagaje normativo, o imaginario social y su nuevo entorno latinoamericano definirá de un modo complejo el yo que es el nosotros frente al otro, a la alteridad, en un difícil continuo de extrañamiento y acercamiento, extranjería y diversidad.

El estudio de la interpelación entre estos colectivos humanos debe ubicarse a su vez en el eje sociohistórico de la dinámica entre inmigración e integración, incorporación y marginalidad. Metodológicamente se abre a su vez la posibilidad de concebir la investigación sobre los judíos de América Latina como una nueva y fresca perspectiva para el estudio de diversas características y tendencias del continente. ${ }^{22}$ Ello exige atender, tanto al elemento étnico de la composición poblacional de los países latinoamericanos. como a las ideologias prevalecientes en torno a la integración nacional. Los diversos grados de estímulo a la integración, así como las fluctuaciones diacrónicas en la actitud hacia ésta, se insertan en el contradictorio desarrollo de los ejes antes señalados. La investigación histórico-social deberá dirigirse entonces hacia los proyectos teóricos y prácticos de construcción de lo nacional -sea desde la óptica de integración nacional, sea desde la de cultura nacional- para ubicar en ellos el espacio y opción concedida al extranjero primero, a las minorías después. Así, la exploración comparativa de diversos proyectos nacionales nos permite arrojar luz simultáneamente sobre el lugar que los diversos nacionalismos han asumido en el proceso de integración nacional y sobre su efecto en la definición del estatuto cívico de los judíos, su incorpo-

21" Raphael Samuel en Joutard, op. cit., p. 298.

${ }^{21}$ Paul Thompson (ed.), Our Common History, op. cit., p. 9-19.

22 Merkx, op. cit., p. 5. 
ración a la sociedad así como sobre la configuración de su identidad. A titulo ejemplar, los ejes del laicismo, del positivismo y de la ideologia del "crisol de raza" han tenido un impacto determinado sobre la inserción e identidad de los judios en Argentina ${ }^{23}$ que debe ser comparado con la experiencia en otros contextos nacionales. Si tomamos el caso de México, el proyecto nacional que se gestó a partir de la pugna teórica y práctica entre liberales y conservadores durante el siglo XIX, pero, sobre todo, aquel que acompańo, orientó y se desarrolló a partir del proceso revolucionario, tuvo un impacto diferencial sobre los judíos así como sobre otros grupos minoritarios. El componente étnico se convirtió en un elemento determinante representado por el mestizaje como realidad y como modelo. Así, los contenidos ideológicos del nacionalismo mexicano se nutrieron de fuentes tan diversas como, para utilizar la terminologia de Brading, el darwinismo social de un Andrés Molina Enríquez o el idealismo romántico de un José Vasconcelos. ${ }^{24}$ La concepción de la nación mexicana basada en la homogeneidad étnica como instrumento de integración nacional, llevó al rechazo de la pluralidad étnica y la diversidad cultural como contrarias a la identidad nacional. De ahi que los grupos étnicos minoritarios, ya fueran indígenas o de inmigración se hayan enfrentado a una alternativa: "o la asimilación total a los patrones mayoritarios y dominantes, o bien la existencia como enclaves culturales, al margen de la sociedad nacional, y sufriendo de hecho el rechazo de ésta". 25

En efecto, el impacto de la compleja dialéctica entre legalidad y legitimidad de la presencia judía en el continente americano puede contribuir a una mejor comprensión de las propias tendencias nacionales y continentales. Todo testimonio oral de identidad, toda percepción individual o grupal de este rico universo de las representaciones y del imaginario colectivo puede contribuir a la investigación sociohistórica y cultural. Metodológicamente, el recurso del análisis comparativo aporta nuevos y esenciales elementos a la investigación. A nivel nacional, es preciso el análisis comparativo entre el grupo judio y otros grupos minoritarios; también a nivel continental. Mas la pregunta de si América Latina es una o varias realidades continua siendo vigente. Recordemos la pluralización del título que Lucien Febvre le dio a aquel número de los Annales dedicado a nuestro continente: "Á Travers les Amériques Latines".

Existe, además, una tercera dimensión en la cual se exige el análisis comparativo y es aquella en la que nuestro marco referencial son los estudios del judaísmo contemporáneo para los cuales las comunidades judías del continente aparecen como un caso especifico en el contexto de otras comunidades judías. ${ }^{26}$ A título de ejemplo, la diversidad de países de procedencia de la inmigración

\footnotetext{
${ }^{23}$ Leonardo Senkman, "Argentine Culture and Jewish Ideatity", en Merkx, op. cit., p. 255-269.

${ }^{24}$ Cf. David Brading, Mito y profecia en la historia de México, México, Ed. Vuelta, 1988.

¿s Rodolfo Stavenhagen, "El nacionalismo mexicano ante las minorias étnicas", Aqui estamos, núm. 2, 1977, México.

${ }_{26}$ Haim Avni, introducción, en Judaica Latinoamericana. Estudios histórico-sociales, Jerusalén, Ed. Universitaria Magness, 1988.
} 
judía al continente es una característica exclusiva de estas comunidades por lo que la dimensión étnica-sectorial interna provee elementos únicos e interesantes de estudio. La llegada de judios ashkenazitas de Europa Oriental y Central, de judios sefarditas del antiguo Imperio Otomano - de los paises balcánicos así como de judios provenientes de los paises árabes- confiere a estas comunidades un interesante mosaico organizativo y de identidad en cuya comprensión la historia oral muestra toda su relevancia. Esta diversidad de pasados significó diferentes experiencias judaicas y variedad de modelos de interacción con las sociedades globales, y se manifestó a su vez, en una pluralidad de ubicación que condicionó comportamientos sociales, modelos de identidad, cosmovisiones y lenguajes.

La situación central del lenguaje, a su vez, como expresión de conciencia, de relaciones humanas, con compleja referencia a la realidad y con toda la fuerza de lo imaginario aparece como un terreno privilegiado para el historiador oral. Mundos vividos o imaginados en yiddish, en ladino o en árabe, y retraducidos al español, recrean en el presente un pasado. De este modo logramos hacer necesariamente complejo el nosotros superando toda visión simplificadora y maniquea, y confiriéndole a toda la heterogeneidad que lo define. Resulta pertinente apuntar en este contexto que es en el proceso mismo de la creación de fuentes, donde habrá de tomarse la decisión, en función de los objetivos perseguidos y del dato generacional, acerca de la importancia o relevancia del idioma en el que se desarrolla la entrevista. Pero no sólo esto. Podemos acudir en este rubro al testimonio que complementa la información de los procesos de estructuración e institucionalización que han caracterizado a la comunidad judia organizada. Aquí resulta de fundamental importancia la confluencia de los diferentes actores sociales, abriéndose la posibilidad de estudiar los aspectos organizativos no sólo desde la óptica del liderazgo o de los representantes, esto es, del centro, sino de aquella periferia humana de los organizados y representados. Cotidianidad, vidas "comunes" para una visión jerarquizante del hacerse histórico, aportan luz sobre los procesos de mediación entre la configuración concreta de las necesidades, su percepción y la acción social que suscita.

Todas las precauciones de método así como técnicas que permiten conferir significación y relevancia al testimonio vivencial deben aplicarse con rigor. ${ }^{27}$ En nuestro caso resulta también esencial la dinámica que se genera entre los diversos ejes organizativos que surgen como respuesta a necesidades y la percepción que de éstas se tiene. Asi, el desarrollo de las coordenadas de las organizaciones asistenciales, religiosas, educativas, culturales, politicas, o de socialización sin más, en su diversidad sectorial, y las de defensa y representación central configuran un amplio mapeo institucional caracterizado por el voluntarismo y la pluralidad organizativa. Si entendemos que la matriz organizativa comunitaria es algo más que una forma de ordenamiento, que es un importante elemento de la dinámica social de la vida judía, su estudio nos permite acceder desde esta óptica a la compleja dinámica entre continuidad 
cultural e integración, que debe ser explorada sincrónica y diacrónicamente. El elemento cronológico puede devenir en un elemento generacional, entendido éste en un amplio sentido sociohistórico en el que se incluyen las normas y patrones de vida que lo caracterizan. Podemos ejemplificar lo dicho, al distinguir los canales y los espacios de incorporación del grupo a la sociedad -económicos, sociales, politicos y culturales- del marco de las propias caracteristicas de las diferentes sociedades latinoamericanas en lo que a composición sociodemográfica, estructuración económica y régimen político se refiere. El impacto diverso de estos procesos en el seno de las diferentes realidades exige el deslinde necesario entre comunidad judia organizada y población judía.

Por último, encontramos otro campo problemático fundamental, y estrechamente ligado al anterior, donde las fuentes orales y testimoniales se encuentran con las fuentes escritas, se complementan y se enriquecen, y nos ofrecen nuevas perspectivas analíticas. Este es, para calificarlo genéricamente, el de las ideologías que los inmigrantes judios trajeron consigo. Estas expresaban, entre otras cosas, el tipo de estatuto cívico e inserción social de los judios en sus paises de origen asi como la naturaleza de las relaciones que mantuvieron con su sociedad global. En el proceso de ser absorbidas en los nuevos contextos sociopolíticos y culturales latinoamericanos, las ideas se incorporaron a nuevos marcos de referencia de la acción, a nuevas necesidades e intereses, sufrieron modificaciones $y$ adquirieron por tanto una nueva significación sociológica, individual y colectiva.

El estudio del sionismo, otras formas de nacionalismo judío, del bundismo y del comunismo, resulta fundamental para comprender la dinámica interna y el desarrollo de las comunidades judias del continente. Visiones diversas en torno a la continuidad grupal y a la incorporación e integración en el seno de la sociedad se confrontaron y polemizaron al intentar definir los contenidos de la vida judia, al modelar el perfil de las instituciones comunitarias y al expresar los lazos de cohesión y solidaridad judia global.

Actas institucionales, documentación partidista, producción periodística, todas ellas son fuentes para su estudio, aunque, aclaremos, no siempre en existencia o completas. Por ello, si a éstas les sumamos el aporte del testimonio oral, no sólo podemos complementarlas sino que nuevamente estamos en posibilidad de trascender cierta interpretación convencional. Al incorporar a activistas y "activados", hombres y mujeres insertos en el centro y en la periferia podemos, en efecto configurar las modalidades diversas de las convicciones y los impactos diferenciales de los acontecimientos así como las sensibilidades frente a ellos. No únicamente el porqué, sino también los diferentes cómos. ${ }^{28}$ En otras palabras, estamos ante la posibilidad no sólo de aclarar también de relacionar la distancia entre la experiencia de amplios grupos y sectores sociales y "las estructuras supraindividuales de la historia". 29 La interacción entre necesidad e ideologia, cotidianidad y racionaliza-

28 James Hoopes, Oral History, The University of North Carolina Press, Chapel Hill, 1979, p. 17.

¿4 Luisa Passerini, "Work Ideology...", op. cit., p. 76. 
ción, resignificación de creencias y ritualización de formulaciones, memoria y "verdad" así como la significación de la distorsión, sólo pueden ser analizadas desde la complementariedad de las fuentes.

De este modo, reencontrando identidad o historia, generando nuevas fuentes para estudiar también viejos problemas, conceptualizando para recuperar en toda su magnitud al método no sólo técnica sino también teóricamente, es a partir del territorio metodológico que podemos construir con complejidad y rigor un conocimiento histórico y social, conscientes de que no sólo el pasado sino también el presente y el futuro son históricos. Redescubriendo al hombre podemos esforzarnos por hacer confluir comprensión y explicación, sentido y tendencias, significado y estructuras. 